\title{
Sphingosine kinase/sphingosine 1-phosphate axis: a new player for insulin-like growth factor-1- induced myoblast differentiation
}

\author{
Caterina Bernacchioni ${ }^{1,2}$, Francesca Cencetti $^{1,2}$, Sabrina Blescia ${ }^{1}$, Chiara Donati ${ }^{1,2+}$ and Paola Bruni ${ }^{1,2^{*}+}$
}

\begin{abstract}
Background: Insulin-like growth factor-1 (IGF-1) is the most important physiological regulator of skeletal muscle progenitor cells, which are responsible for adult skeletal muscle regeneration. The ability of IGF-1 to affect multiple aspects of skeletal muscle cell biology such as proliferation, differentiation, survival and motility is well recognized, although the molecular mechanisms implicated in its complex biological action are not fully defined. Since sphingosine 1-phosphate (S1P) has recently emerged as a key player in skeletal muscle regeneration, we investigated the possible involvement of the sphingosine kinase (SK)/S1P receptor axis on the biological effects of IGF-1 in murine myoblasts.

Methods: RNA interference, chemical inhibition and immunofluorescence approaches were used to assess the role of the SK/S1P axis on the myogenic and mitogenic effects of IGF-1 in C2C12 myoblasts.

Results: We show that IGF-1 increases SK activity in mouse myoblasts. The effect of the growth factor does not involve transcriptional regulation of SK1 or SK2, since the protein content of both isoforms is not affected; rather, IGF-1 enhances the fraction of the active form of SK. Moreover, transactivation of the $\mathrm{S}_{1} \mathrm{P}_{2}$ receptor induced by IGF-1 via SK activation appears to be involved in the myogenic effect of the growth factor. Indeed, the prodifferentiating effect of IGF-1 in myoblasts is impaired when SK activity is pharmacologically inhibited, or SK1 or SK2 are specifically silenced, or the $\mathrm{SIP}_{2}$ receptor is downregulated. Furthermore, in this study we show that IGF-1 transactivates $S 1 \mathrm{P}_{1} / \mathrm{S}_{1} \mathrm{P}_{3}$ receptors via SK activation and that this molecular event negatively regulates the mitogenic effect elicited by the growth factor, since the specific silencing of $\mathrm{S}_{1} \mathrm{P}_{1}$ or $\mathrm{S}_{1} \mathrm{P}_{3}$ receptors increases cell proliferation induced by IGF-1.

Conclusions: We demonstrate a dual role of the SK/S1P axis in response to myoblast challenge with IGF-1, that likely is important to regulate the biological effect of this growth factor. These findings add new information to the understanding of the mechanism by which IGF-1 regulates skeletal muscle regeneration.
\end{abstract}

Keywords: IGF-1, Myoblasts, Myogenic differentiation, Sphingosine 1-phosphate, Sphingosine kinase, Sphingosine 1 -phospate receptors

\footnotetext{
* Correspondence: paola.bruni@unifi.it

${ }^{\dagger}$ Equal contributors

'Department of Biochemical Sciences, University of Florence, GB Morgagni

50, 50134 Florence, Italy

${ }^{2}$ Interuniversity Institute of Myology (IIM), Padova, Italy
} 


\section{Background}

Sphingosine 1-phosphate (S1P) is a bioactive lipid that is physiologically present in serum and capable of regulating multiple essential cellular processes, including cell growth and survival, cell motility and invasion, angiogenesis, lymphocyte trafficking and immune regulation. S1P is synthesized from sphingosine by a phosphorylation reaction catalyzed by the sphingosine kinases (SKs) SK1 and SK2, which are highly conserved enzymes activated by numerous stimuli [1]. S1P levels are tightly regulated by the balance between biosynthesis catalyzed by SKs, reversible conversion to sphingosine mediated by specific and non-specific lipid phosphatases, and S1P lyase (SPL)-dependent degradation [2,3]. S1P exerts its functions either as a second messenger or as a ligand of five specific G-protein coupled receptors named S1P receptors (S1PR). S1PR are differentially coupled to one or multiple G-proteins and they can activate a variety of signaling pathways determining distinct and even contrasting final cellular effects.

Recently it has emerged that S1P plays a key role in the biology of skeletal muscle progenitor cells [4]. Indeed, the bioactive sphingolipid exerts a strong mitogenic action in satellite cells [5] and also stimulates their cell motility [6], whereas in myoblasts it behaves as prodifferentiating [7] and chemorepellant cue [8]. Our recent findings have demonstrated that the S1P signaling axis, under the control of a number of physiological and pathophysiological extracellular agents such as tumor necrosis factor $\alpha$ (TNF $\alpha)$, platelet-derived growth factor (PDGF) and transforming growth factor $\beta$ (TGF $\beta$ ) [9-11], is the mediator of fundamental biological responses evoked by the above mentioned agonists. The obtained results are in keeping with a very complex mechanism of action of S1P that can have both beneficial and unfavorable effects on skeletal muscle regeneration. Indeed, we have demonstrated that endogenous S1P metabolism, stimulated by SK1 activation and $\mathrm{S}_{1} \mathrm{P}_{1}$ engagement, is critical for myoblast motility and attenuation of the mitogenic response elicited by PDGF [11]; however, we have also shown that the SK/S1P axis is exploited by TGF $\beta$ to convey its detrimental pro-fibrotic effect and that upregulation of S1P metabolism mediated by SK1 together with enhanced expression of $\mathrm{S}_{1} \mathrm{P}_{3}$ account for transdifferentiation of myoblasts into myofibroblasts, which are responsible for deposition of extracellular matrix protein [9].

Insulin-like growth factor 1 (IGF-1) is a hormone peptide that, beside being released into the blood from the liver, can be synthesized by the target tissues, including skeletal muscle, where IGF-1 concentrations are locally regulated. IGF-1 plays a key role in skeletal muscle regeneration as it is able to stimulate myoblast proliferation [12]. Moreover, unlike other growth factors, IGF-1 also stimulates myogenic differentiation and induces myocyte hypertrophy [12], supporting the notion that IGF-1 is a master regulator of skeletal muscle biology. These seemingly contradictory roles of the growth factor highlight the importance of understanding how IGF-1 cooperates with other mitogenic and differentiating stimuli to induce either, or both, these events. In this regard, given the fundamental role of IGF-1 in skeletal muscle and its incompletely defined mechanism of action, we focused on the possible involvement of the SK/S1P axis on the biological effect of the growth factor. Data reported here demonstrate for the first time that IGF-1 activates SKs in mouse myoblasts. The consequent $\mathrm{S}_{2} \mathrm{P}_{2}$ transactivation appears to be implicated in the myogenic effect of the growth factor. Moreover, the engagement of $\mathrm{S}_{1} \mathrm{P}_{1} /$ $\mathrm{S} \mathrm{P}_{3}$ in IGF-1 signaling, via a mechanism dependent on SK activation, inhibits myoblast proliferation, which points to a role for the SK/S1P axis in the control of the biological outcome of IGF-1 in skeletal muscle.

These results highlight a new role for the SK/S1P axis in IGF-1-regulated signaling which is important for the biological response exerted by the growth factor. This could be exploited to improve skeletal muscle regeneration.

\section{Methods}

\section{Materials}

All biochemicals, TRI reagent, cell culture reagents, DMEM, fetal calf serum, protease inhibitor cocktail, monoclonal anti-skeletal fast myosin heavy chain (MHC) (clone MY-32), bovine serum albumin (BSA) were purchased from Sigma-Aldrich (St Louis, MO, USA). Mouse skeletal muscle $\mathrm{C} 2 \mathrm{C} 12$ cells were obtained from the American Type Culture Collection (Manassas, VA, USA). Propidium iodide was obtained from Calbiochem (San Diego, CA, USA). Recombinant IGF-1 was obtained from PeproTech (London, UK). SKI-2 [2-(p-hydroxyanilino)-4(p-chlorophenyl)thiazole] and U0126 were obtained from Calbiochem. siRNA duplexes corresponding to two DNA target sequences of mouse SK1 (5'UAGGAACUGUGGC CUCUAAdTdT3', 5'GUGUUAUGCAUCUGUUCUAdT dT3'), mouse SK2 (5' GCCUACUUCUGCAUCUACAdT dT3'; 5'CCUCAUACAGACAGAACGAdTdT3'), mouse S1P $_{1}$ (5'UCACCUACUACUGUUAGAdTdT3'; 5'CUU GCUAACUAUUUGGAAAdTdT3'), mouse $\mathrm{S}^{\prime} \mathrm{P}_{2}\left(5^{\prime} \mathrm{CU}\right.$ CUGUACGUCCGAAUGUAdTdT3', 5'GACUAAUCA GAUUGUAGUAdTdT3'), mouse $\mathrm{S}^{\prime} \mathrm{P}_{3}$ (SASI_Mm01_ 00145232, SASI_Mm01_00145233), mouse S1P 4 (SASI_ Mm01_00094192, SASI_Mm01_00094193), mouse SPL (SASI_Mm01_00122643) and scrambled siRNA (5' UUCUCCGAACGUGUCACGUdTdT3') were obtained from Sigma-Proligo (The Woodlands, TX, USA). Lipofectamine RNAiMAX was purchased from Invitrogen (Carlsbad, CA, USA). Enhanced chemiluminescence 
reagents and $\left[\gamma_{-}{ }^{32} \mathrm{P}\right]$ ATP $(3000 \mathrm{Ci} / \mathrm{mmol})$ were obtained from GE Healthcare Europe (Milan, Italy). Secondary antibodies conjugated to horseradish peroxidase, monoclonal anti- $\beta$-actin and monoclonal anti-myogenin antibodies were obtained from Santa Cruz Biotechnology (Santa Cruz, CA, USA). Monoclonal anti-caveolin-3 antibodies were from BD Biosciences Transduction Laboratories (Lexington, KY, USA). Specific anti-SK1 polyclonal antibodies (directed against the 16 carboxyterminal amino acids of the mouse SK1) [13] were kindly provided by Dr Y Banno (Gifu University School of Medicine, Gifu, Japan). Rabbit polyclonal antibodies generated against SK2 [14] were a kind gift from Dr S
Nakamura (Department of Molecular and Cellular Biology, Kobe University Graduate School of Medicine, Kobe, Japan). Phospho-human SK1 specific polyclonal antibodies (directed against the phosphopeptide CGSKTPApSPVVVQQ centered around phospho-Ser ${ }^{225}$ of human SK1) [15] were kindly provided by Dr S Pitson (Hanson Institute, institute of Medical and Veterinary Science, Adelaide, Australia). Fluorescein-conjugated horse anti-mouse secondary antibodies were obtained from Vector Laboratories (Burlingame, CA, USA). Specific polyclonal rabbit anti-mouse SPL antibodies (directed against the C-terminal peptide 551TTDPVTQGNQMNGSPKPR-568) [16] were a kind gift from Dr RL Proia (National Institute of Diabetes and

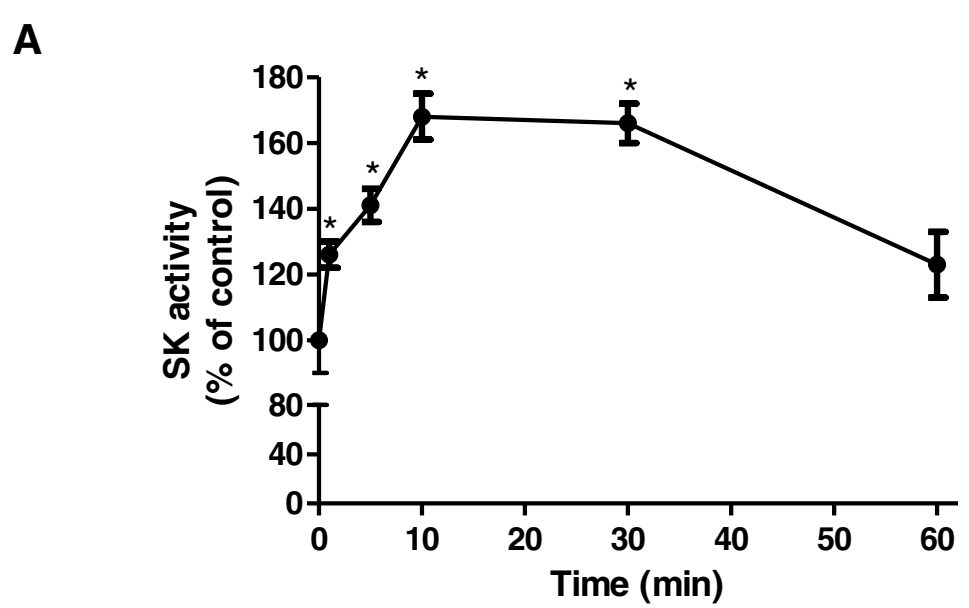

B

IGF-1 (min)

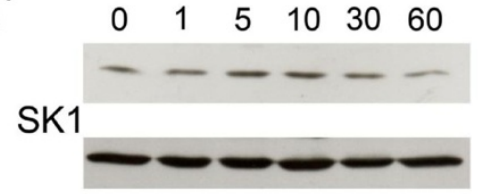

cytosol

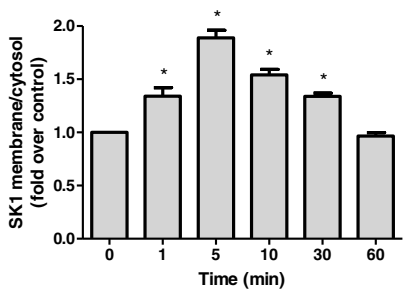

$\underset{(\min )}{\mathrm{IGF}-1}$

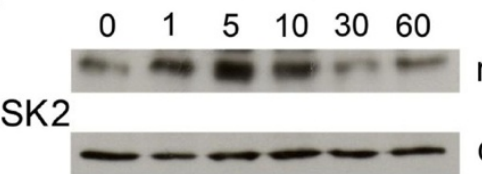

membrane cytosol

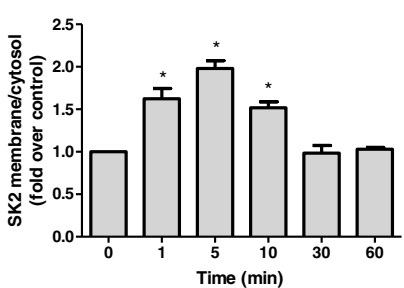

Figure 1 Effect of insulin-like growth factor-1 on sphingosine kinase activity and subcellular localization. Serum-starved myoblasts were incubated with $50 \mathrm{ng} / \mathrm{ml}$ insulin-like growth factor-1 (IGF-1) for the indicated time intervals. (A) Aliquots of cell extracts (40 $\mu \mathrm{g})$ were used to determine sphingosine kinase (SK) activity. Data represent the mean \pm SEM of at least three independent experiments, each performed at least in duplicate. The effect of IGF-1 in challenged versus unchallenged cells was statistically significant by Student's $t$ test $(* P<0.05)$. (B) Western analysis of SK1 (upper panel) and SK2 (lower panel) were performed in membrane and cytosolic fractions. Blots representative of at least three independent experiments are shown. The histograms represent densitometric analysis of three independent experiments. Data reported are expressed as -fold increase of the membrane:cytosol ratio. The increase of SK1 and SK2 membrane content induced by IGF-1 was statistically significant by Student's t-test $(* P<0.05)$. 
Digestive and Kidney Disease, National Institute of Health, Bethesda, USA). All reagents and probes required to perform real-time PCR were from Applied Biosystems (Foster City, CA, USA). $\left[{ }^{3} \mathrm{H}\right.$ ]thymidine $(20 \mathrm{Ci} / \mathrm{mmol})$ was from Perkin Elmer (Waltham, MA, USA).

\section{Cell culture}

Murine $\mathrm{C} 2 \mathrm{C} 12$ myoblasts were routinely grown in DMEM supplemented with $10 \%$ fetal calf serum, $2 \mathrm{mM}$
L-glutamine, $100 \mathrm{U} / \mathrm{ml}$ penicillin, and $100 \mu \mathrm{g} / \mathrm{ml}$ streptomycin at $37^{\circ} \mathrm{C}$ in $5 \% \mathrm{CO}_{2}$. For myogenic differentiation experiments, cells were seeded in p35 plates, and when 90\% confluent they were shifted to DMEM without serum containing $1 \mathrm{mg} / \mathrm{ml}$ BSA. For proliferation experiments, cells were seeded in 12-well plates and utilized when approximately $50 \%$ confluent.

When requested, cells were incubated with inhibitors 30 minutes before challenge with IGF-1.

A

IGF-1

$\begin{array}{lllllll}(\min ) & 0 & 1 & 5 & 10 & 30 & 60\end{array}$

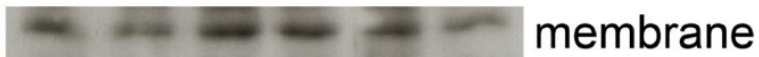

P-SK1
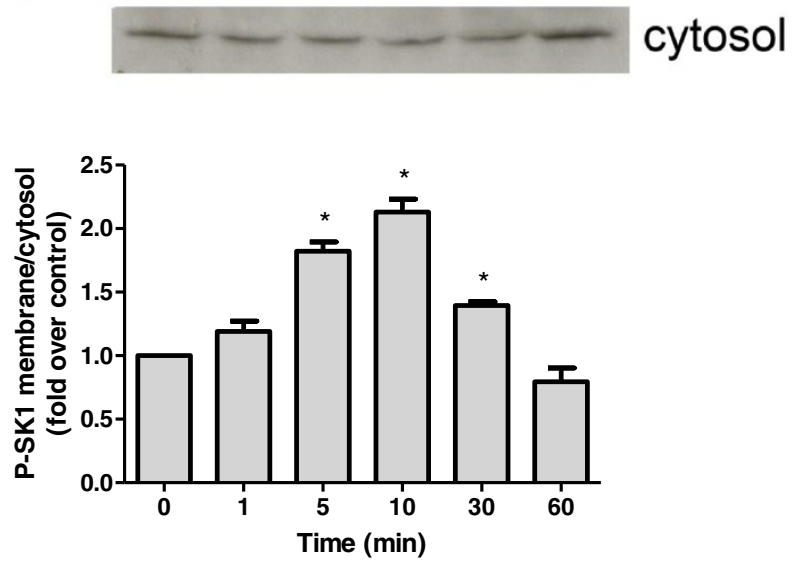

B

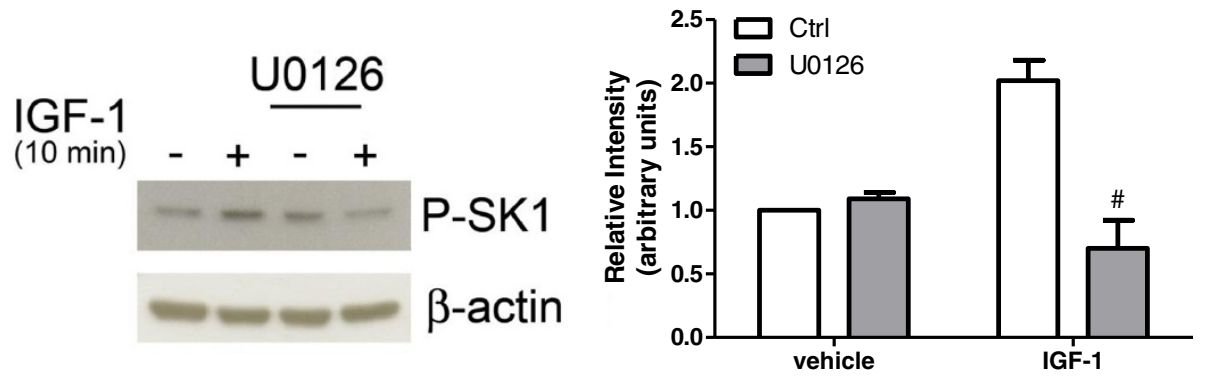

Figure 2 Sphingosine kinase-1 phosphorylation induced by insulin-like growth factor-1 is mediated by ERK $\mathbf{1 / 2}$. (A) Western blot analysis was performed using specific anti-phospho-sphingosine kinase (SK)1 antibody in membrane and cytosolic fractions prepared from serum-starved myoblasts treated with $50 \mathrm{ng} / \mathrm{ml}$ insulin-like growth factor-1 (IGF-1) for the indicated time intervals. A blot representative of at least three independent experiments with analogous results is shown. The histogram represents densitometric analysis of three independent experiments. Data reported are expressed as -fold increase of the membrane:cytosol ratio. The increase of phospho-SK1 membrane content induced by IGF-1 was statistically significant by Student's $t$ test $\left({ }^{*} P<0.05\right)$. (B) Serum-starved myoblasts were pre-incubated for 30 minutes with ERK1/2 specific inhibitor (5 $\mu \mathrm{M}$ U0126) before being challenged with $50 \mathrm{ng} / \mathrm{ml} \mathrm{IGF-1} \mathrm{for} 10$ minutes. Cell lysates were separated by SDS-PAGE and immunoblotted using specific anti-phospho-SK1 and anti- $\beta$-actin antibodies. A blot representative of at least three independent experiments is shown. In the histogram band intensity corresponding to phosphorylated SK1 was normalized to $\beta$-actin and reported as mean \pm SEM of three independent experiments, -fold change over control (set as 1). SK1 phosphorylation in IGF-1-challenged cells was significantly reduced by U0126 pre-incubation (Student's t test, $\# P<0.05$ ). 


\section{Sphingosine kinase activity assay}

SK activity was measured as described by Olivera and colleagues [17] with a few modifications, as described previously [10]. Specific activity of SK was expressed as picomoles of S1P formed per minute per milligram of protein.

\section{Cell transfection}

C2C12 cells were transfected with Lipofectamine RNAiMAX according to the manufacturer's instructions. Briefly, Lipofectamine RNAiMAX was incubated with siRNA in DMEM without serum and antibiotics at room temperature for 20 minutes, and afterwards the lipid/ RNA complexes were added with gentle agitation to $\mathrm{C} 2 \mathrm{C} 12$ cells to a final concentration of $50 \mathrm{nM}$ in serum containing DMEM. After $24 \mathrm{~h}$, cells were shifted to DMEM without serum containing $1 \mathrm{mg} / \mathrm{ml} \mathrm{BSA}$ and then used for the experiments within $48 \mathrm{~h}$ from the beginning of transfection. The specific gene knockdown was evaluated by Western blot analysis or alternatively by real-time PCR.

\section{Cellular fractionation}

The medium of control and agonist-treated C2C12 cells was removed and the cells were washed twice with icecold PBS, scraped, and collected by centrifugation $(1000 \times \mathrm{g})$. Cells were dispersed in a buffer solution containing $10 \mathrm{mM}$ HEPES, pH 7.4, 1 mM EGTA, $1 \mathrm{mM}$ EDTA, $250 \mathrm{mM}$ sucrose, $5 \mathrm{mM} \mathrm{NaN}_{3}$, and protease inhibitors (1 mM 4-(2-aminoethyl)benzenesulfonyl fluoride,
(AEBSF) $0.3 \mu \mathrm{M}$ aprotinin, $10 \mu \mathrm{g} / \mathrm{ml}$ leupeptin and 10 $\mu \mathrm{g} / \mathrm{ml}$ pepstatin) and disrupted in a Dounce homogenizer (100 strokes). Lysates were centrifuged (10 minutes, $800 \times \mathrm{g})$ and the resulting supernatant was centrifuged again at $200,000 \times \mathrm{g}$ for $1 \mathrm{~h}$ to separate cytosolic and total particulate fractions.

\section{Western blot analysis}

C2C12 cells were lysed for 30 minutes at $4^{\circ} \mathrm{C}$ in a buffer containing $50 \mathrm{mM}$ Tris, $\mathrm{pH} 7.5,120 \mathrm{mM} \mathrm{NaCl}, 1 \mathrm{mM}$ EDTA, 6 mM EGTA, 15 mM Na $\mathrm{P}_{2} \mathrm{O}_{7}, 20 \mathrm{mM} \mathrm{NaF}, 1 \%$ Nonidet and protease inhibitor cocktail (1.04 $\mathrm{mM}$ AEBSF, $0.08 \mu \mathrm{M}$ aprotinin, $0.02 \mathrm{mM}$ leupeptin, $0.04 \mathrm{mM}$ bestatin, $15 \mu \mathrm{M}$ pepstatin A, and $14 \mu \mathrm{M}$ E-64). To prepare total cell lysates, cell extracts were centrifuged for 15 minutes at $10,000 \times \mathrm{g}$ at $4^{\circ} \mathrm{C}$. Proteins from cell lysates, cytosolic and membrane fractions were resuspended in Laemmli's SDS sample buffer. Samples were subjected to SDS-PAGE for 90 minutes at $100 \mathrm{~mA}$ before transfer of proteins to PVDF membranes. Membranes were incubated overnight with the primary antibodies at $4^{\circ} \mathrm{C}$ and then with specific secondary antibodies for $1 \mathrm{~h}$ at room temperature. Bound antibodies were detected by chemiluminescence.

\section{Cell immunofluorescence}

Cells were seeded on microscope slides, pre-coated with $2 \%$ gelatine, and then pre-incubated with SK specific inhibitor $(10 \mu \mathrm{M}$ SKI-2) before being challenged with 50 $\mathrm{ng} / \mathrm{ml}$ IGF-1. After $72 \mathrm{~h}$ cells were fixed in $2 \%$

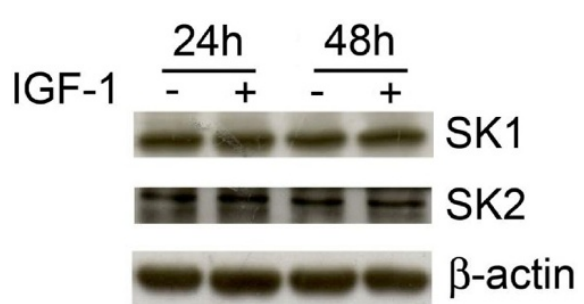

SK1

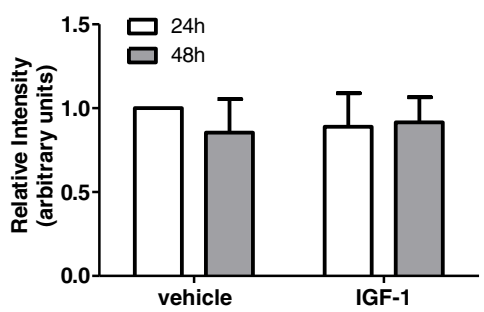

SK2

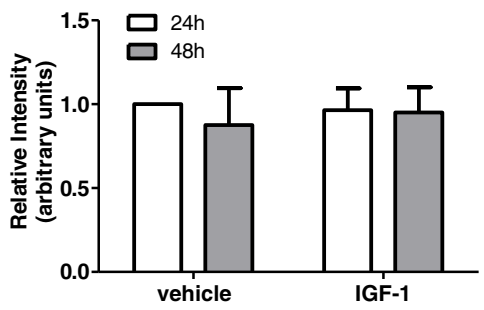

Figure 3 Insulin-like growth factor-1 does not affect sphingosine kinase-1 or sphingosine kinase-2 protein content. $C 2 C 12$ myoblasts were incubated with DMEM containing $1 \mathrm{mg} / \mathrm{ml}$ bovine serum albumin (BSA) for the indicated time intervals in the absence (-) or in the presence (+) of $50 \mathrm{ng} / \mathrm{ml}$ insulin-like growth factor-1 (IGF-1). Top, aliquots of total cell lysates were used to perform Western analysis, using specific anti-sphingosine kinase (SK)1 and anti-SK2 antibodies. A representative blot is shown. Bottom, densitometric analysis of at least three independent experiments. Data are the mean \pm SEM and are reported as protein expression normalized to $\beta$-actin, -fold change over control (set as 1). 
A

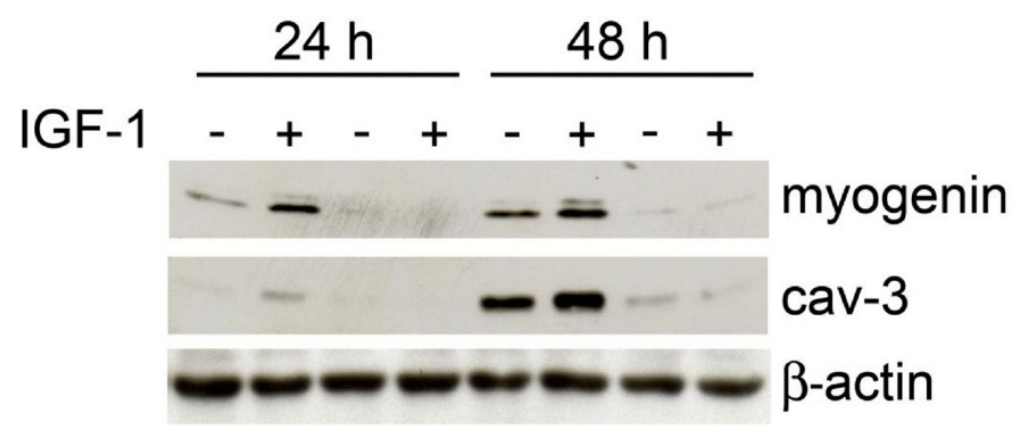

SKI-2 - $-++\quad-\quad+\quad+$

myogenin

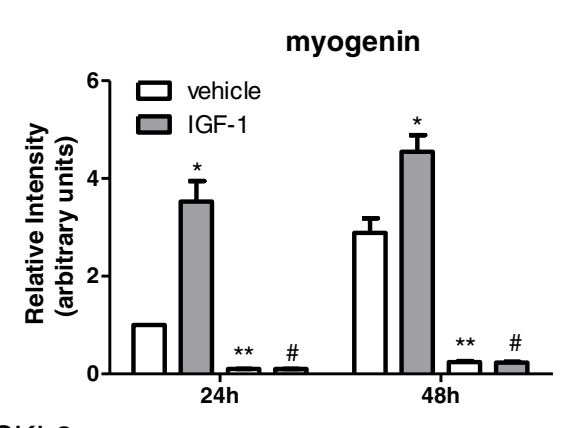

SKI-2

$-++-\quad++$ caveolin-3

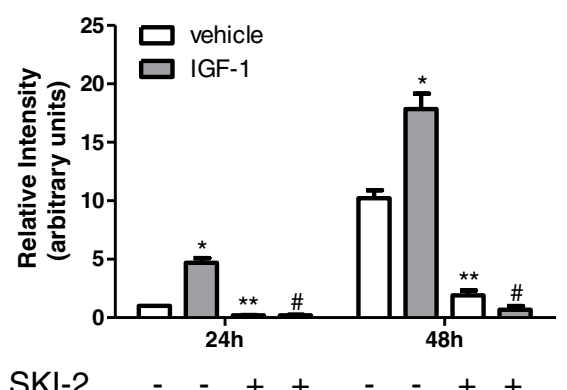

B

IGF-1
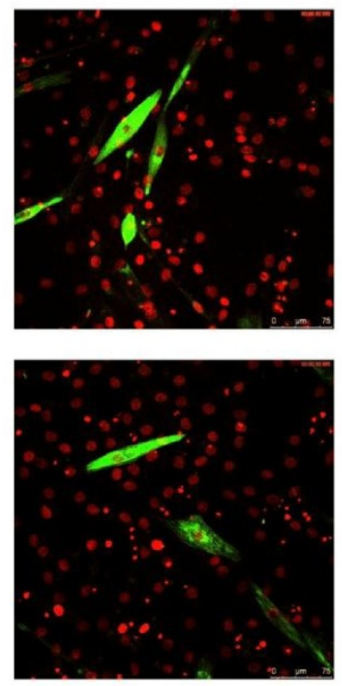

$+$
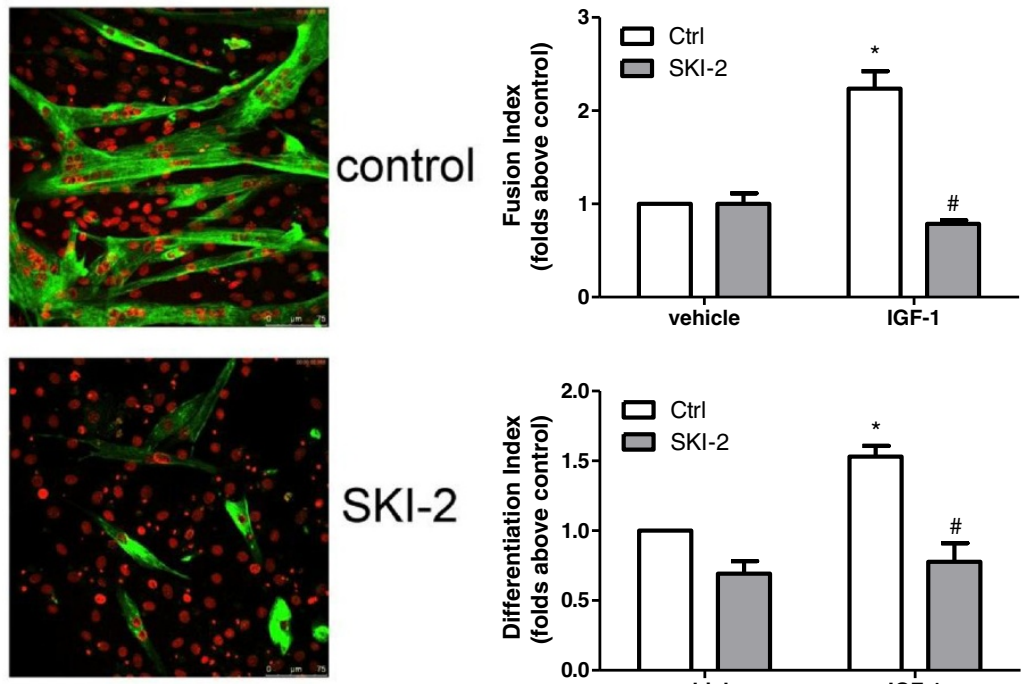

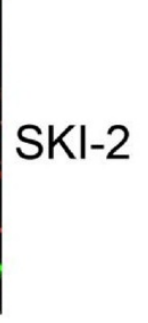

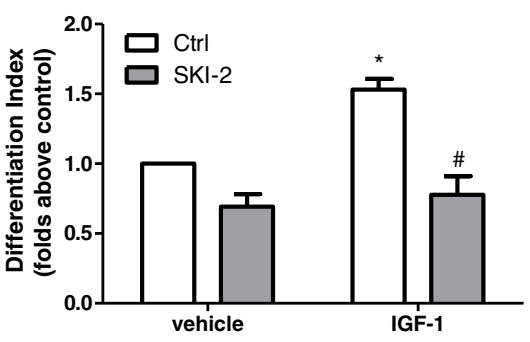




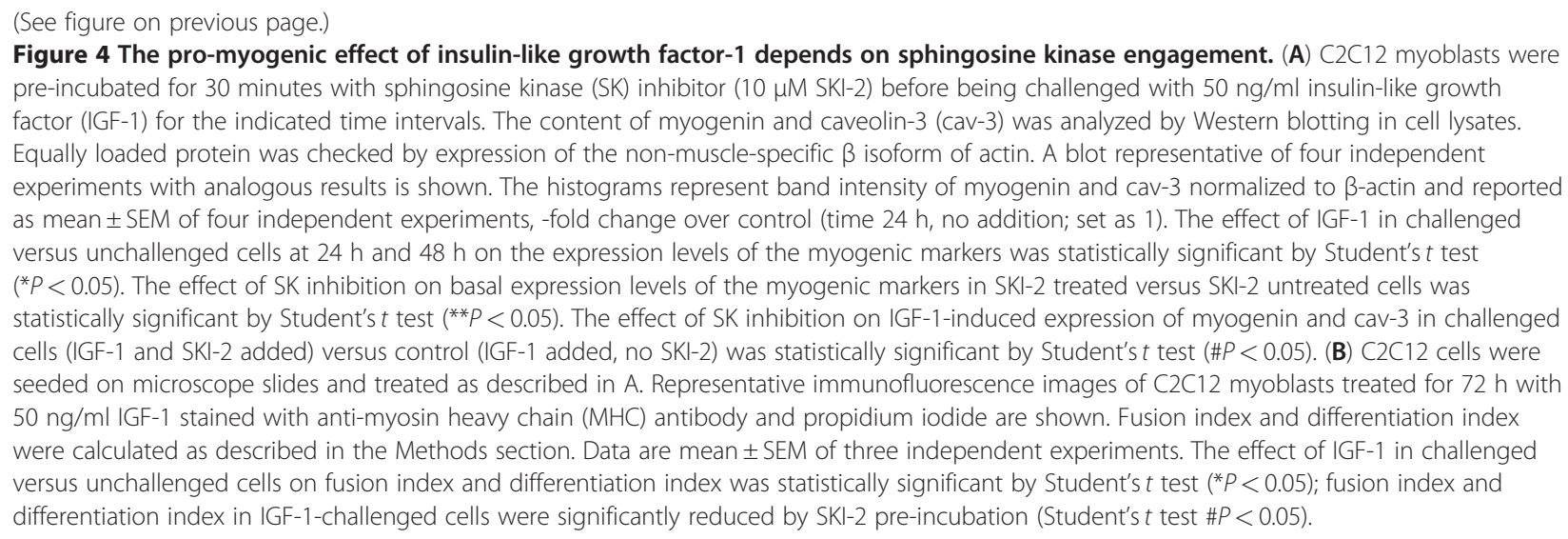

paraformaldehyde in PBS for 20 minutes and permeabilized in $0.1 \%$ Triton X-100-PBS for 30 minutes. Cells were then blocked in 3\% BSA for $1 \mathrm{~h}$ and incubated with anti-MHC antibody for $2 \mathrm{~h}$ and fluorescein-conjugated anti-mouse secondary antibody for $1 \mathrm{~h}$. To stain nuclei, the specimen was incubated with $50 \mu \mathrm{g} / \mathrm{ml}$ propidium iodide in PBS for 15 minutes. Images were obtained using a Leica SP5 laser scanning confocal microscope (Leica Microsystems GmbH, Wetzlar, Germany) with a $40 \times$ objective. To quantify the differentiation and fusion of $\mathrm{C} 2 \mathrm{C} 12$ cells after treatment, we calculated the differentiation index as the percentage of MHC-positive cells above total nuclei and the fusion index as the average number of nuclei in MHC-positive cells with at least three nuclei above total number of nuclei, respectively.

\section{Quantitative real-time reverse transcription PCR}

Total RNA $(2 \mu \mathrm{g})$, extracted with TRI reagent from C2C12 myoblasts, was reverse transcribed using the high capacity cDNA reverse transcription kit (Applied Biosystems). The quantification of S1PR mRNA was performed by real-time PCR employing TaqMan gene expression assays. Each measurement was carried out in triplicate, using the automated ABI Prism 7700 Sequence Detector System (Applied Biosystems) as described previously [18], by simultaneous amplification

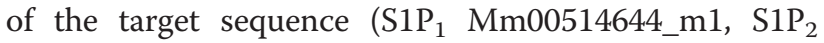
Mm01177794_m1, S1P 3 Mm00515669_m1, and ${\mathrm{S} 1 \mathrm{P}_{4}}_{4}$ Mm00468695_s1; Applied Biosystems) together with the housekeeping gene $18 \mathrm{~S}$ rRNA. Results were analyzed by ABI Prism Sequence Detection System software, version 1.7 (Applied Biosystems). The $2^{-\Delta \Delta \mathrm{CT}}$ method was applied as a comparative method of quantification [19], and data were normalized to ribosomal $18 \mathrm{~S}$ RNA expression.

\section{Cell proliferation}

Cell proliferation was determined by measuring $\left[{ }^{3} \mathrm{H}\right]$ Thymidine incorporation; $\mathrm{C} 2 \mathrm{C} 12$ cells were serum- starved for $24 \mathrm{~h}$ and then challenged with or without 50 ng/ml IGF-1 for $16 \mathrm{~h} .\left[{ }^{3} \mathrm{H}\right]$ Thymidine $(1 \mu \mathrm{Ci} /$ well $)$ was added for the last $1 \mathrm{~h}$ of incubation. Cells were washed twice in ice-cold PBS before the addition of $500 \mu \mathrm{l}$ of $10 \%$ trichloroacetic acid for 5 minutes at $4^{\circ} \mathrm{C}$. Cells were washed again in ice-cold PBS, and $250 \mu$ of ethanol:ether $(3: 1 \mathrm{v} / \mathrm{v})$ was added to the insoluble material. Samples were then lysed in $0.25 \mathrm{~N} \mathrm{NaOH}$ for $1 \mathrm{~h}$ at $37^{\circ} \mathrm{C}$. Incorporation of $\left[{ }^{3} \mathrm{H}\right]$ Thymidine was measured by scintillation counting.

\section{Statistical analysis}

Statistical analysis was performed using Student's $t$ test. Graphical representations were performed using Prism 5.0 (GraphPad Software, San Diego, CA, USA). Densitometric analysis of the Western blot bands was performed using imaging and analysis software Quantity One (BioRad Laboratories, Hercules, CA, USA).

\section{Results}

Insulin-like growth factor-1 stimulates sphingosine kinase in $\mathrm{C} 2 \mathrm{C} 12$ myoblasts

To explore whether the SK/S1P axis is involved in IGF-1 biological action, we first examined whether the growth factor was capable of regulating SK activity in $\mathrm{C} 2 \mathrm{C} 12$ cells. Data illustrated in Figure $1 \mathrm{~A}$ show that $50 \mathrm{ng} / \mathrm{ml}$ IGF-1 stimulated SK activity. Indeed, the growth factor rapidly and transiently increased SK activity, peaking at 10 minutes and returning to basal level at 60 minutes. In agreement, as shown in Figure 1B, myoblast treatment with $50 \mathrm{ng} / \mathrm{ml} \mathrm{IGF-1} \mathrm{was} \mathrm{responsible} \mathrm{for} \mathrm{rapid} \mathrm{and} \mathrm{tran-}$ sient translocation of both enzyme isoforms, SK1 and SK2, to membrane fraction that was appreciable within 1 minute of incubation, reached the maximal effect at 5 minutes and declined thereafter, thus enhancing the amount of active form of the two enzymes with a favorable access to the hydrophobic substrate sphingosine. 
A
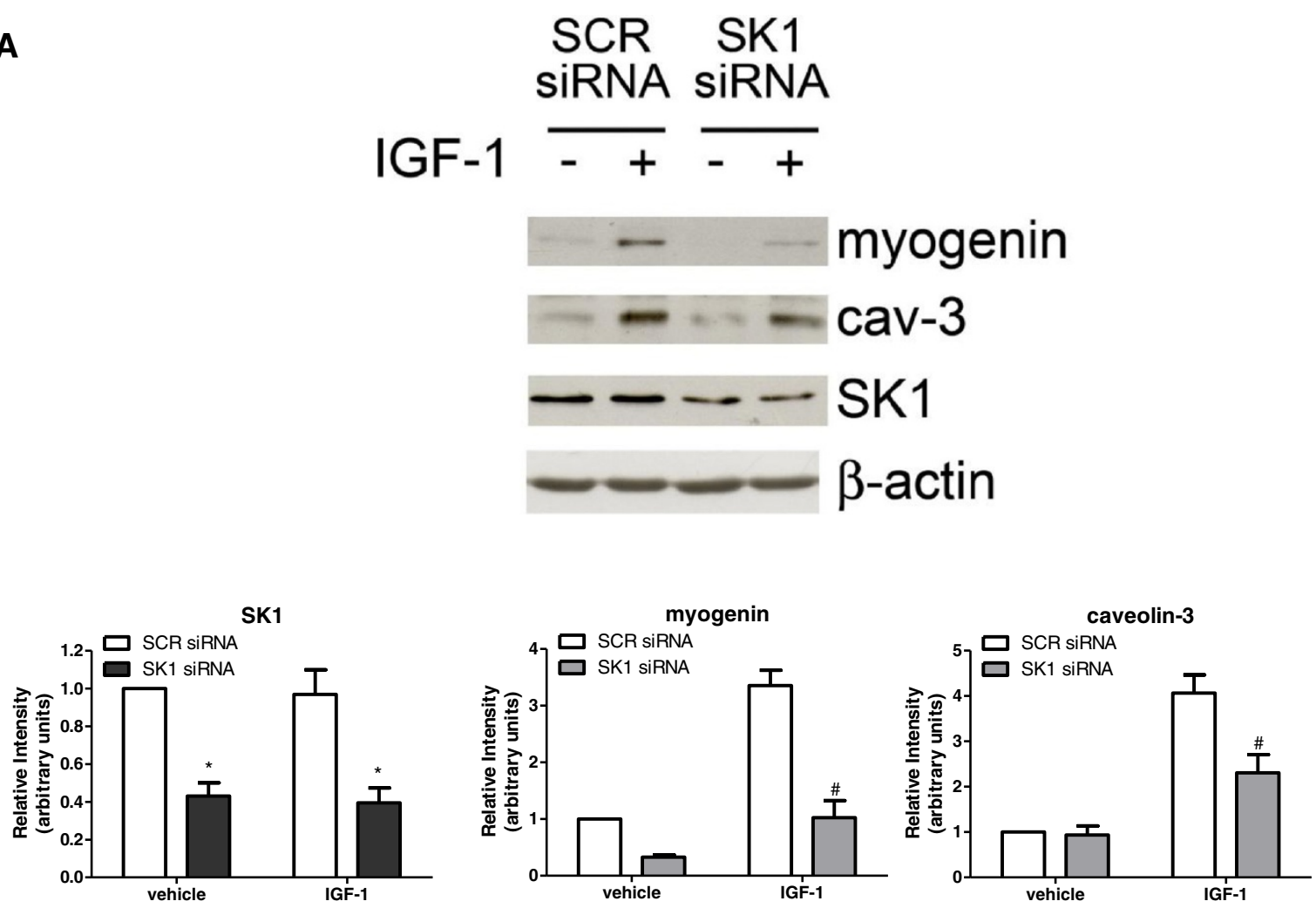

B
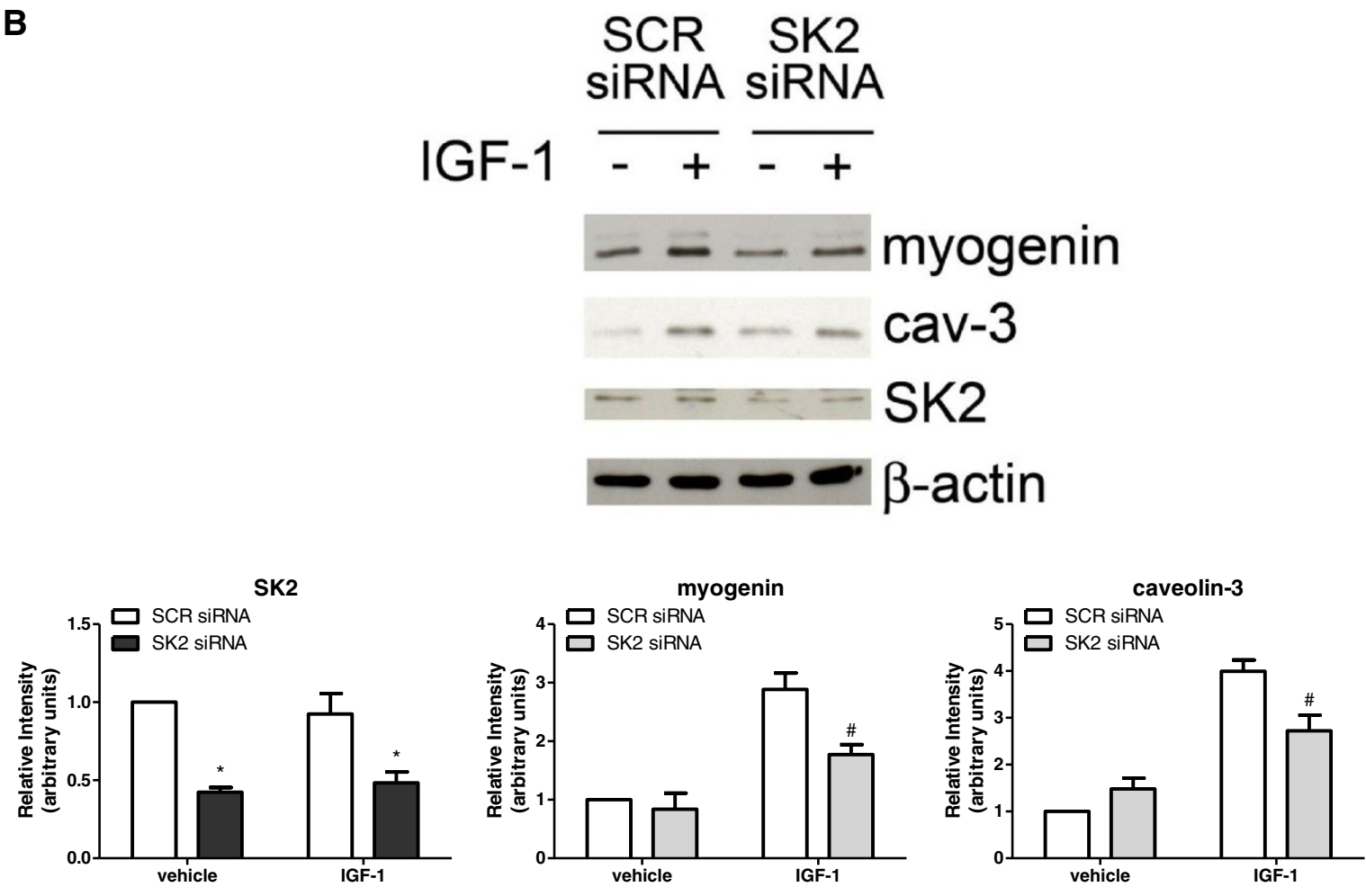
(See figure on previous page.)

Figure 5 The pro-myogenic effect of insulin-like growth factor-1 depends on sphingosine kinase-1 and sphingosine kinase-2 engagement. (A) C2C12 myoblasts, transfected with scrambled (SCR) or sphingosine kinase (SK)1-siRNA were challenged with 50 ng/ml insulin-like growth factor-1 (IGF-1) for the last $24 \mathrm{~h}$ of transfection. Western analysis of SK1 and skeletal muscle marker proteins were performed in cell lysates. Equally loaded protein was checked by expression of the non-muscle-specific $\beta$ isoform of actin. A blot representative of three independent experiments with analogous results is shown. The histograms represent band intensity of SK1, myogenin and caveolin-3 (cav-3) normalized to $\beta$-actin and reported as mean \pm SEM of three independent experiments, -fold change over control (time 24 h, no addition; set as 1). (B) Myoblasts transfected with SCR- or SK2-siRNA were treated and used as described in A. SK silencing in SK1- and SK2-siRNA transfected cells versus SCR-siRNA transfected cells was statistically significant ( $\left.{ }^{*} P<0.05\right)$. The effect of SK downregulation on IGF-1-induced expression of myogenin and caveolin-3 in IGF-1-challenged, SK-siRNA transfected cells versus control (IGF-1 added, SCR-siRNA transfection) was statistically significant by Student's t test $(\# P<0.05)$.

Since agonist-induced stimulation of SK1 activity and translocation of the enzyme to the plasma membrane appears to be mediated by ERK1/2 phosphorylation at $\operatorname{Ser}^{225}$ [15], Western blot analysis using a specific antiphospho-SK1 antibody was performed in myoblast subcellular fractions following IGF-1 treatment. Data reported in Figure 2A show that cell challenge with 50 $\mathrm{ng} / \mathrm{ml}$ IGF-1 resulted in a rapid increase in the phosphorylation of membrane-associated SK1, already detectable at 5 minutes with a maximum at 10 minutes of incubation. Interestingly, the kinetic of membrane translocation of phospho-SK1 was consistent with the timecourse of enzyme activation induced by IGF-1 (Figure 1). Given the ability of IGF-1 to activate the ERK1/2 signaling pathway through its receptor, we analyzed the involvement of this pathway in the activation of SK1 induced by the growth factor. For this purpose, cells were treated with $5 \mu \mathrm{M}$ U0126, a specific pharmacological inhibitor of the ERK1/2 pathway, 30 minutes before IGF-1 challenge. Results presented in Figure 2B show that the inhibition of the ERK1/2 pathway prevented SK1 phosphorylation induced by 10 minutes treatment with IGF-1, demonstrating that the activation of SK1 induced by the growth factor was mediated by ERK1/2.

We then investigated whether IGF-1 was also able to regulate the protein content of SK1 and SK2. As illustrated in Figure 3, Western blot analysis shows that myoblast treatment with $50 \mathrm{ng} / \mathrm{ml}$ IGF- 1 for $24 \mathrm{~h}$ or $48 \mathrm{~h}$ did not affect SK1 or SK2 protein levels, ruling out this possibility.

\section{Involvement of sphingosine kinase in the myogenic effect of insulin-like growth factor-1}

To confirm the ability of IGF-1 to promote myoblast differentiation, the expression of skeletal muscle marker proteins such as myogenin and caveolin-3, normally absent in immature myoblasts but strongly expressed in differentiated cells, was determined by Western analysis. Results presented in Figure 4A show that the expression of myogenic markers in unchallenged serum-deprived myoblasts was enhanced in a time-dependent manner, in agreement with the release of autocrine differentiation factors [20,21]. As expected, myoblast treatment with 50 ng/ml IGF-1 strongly increased the expression of both the myogenic markers at 24 and $48 \mathrm{~h}$. The possible involvement of SK in the myogenic effect of the growth factor was then investigated. To this aim, C2C12 myoblasts were treated with SKI-2, a specific pharmacological inhibitor of SK, already successfully used to block the enzymatic activity in these cells [10]. In agreement with the established role of the SK/S1P axis in myogenesis [7,22], 30 minutes pre-incubation with $10 \mu \mathrm{M}$ SKI-2 significantly decreased the protein content of myogenin and caveolin-3 in unchallenged cells (Figure 4A). Interestingly, cell treatment with the inhibitor completely reversed the enhanced expression of the two myogenic markers induced by IGF-1 at all the examined timeintervals, suggesting a key role of SK in IGF-1-induced myogenesis. In keeping with its well established promyogenic action, IGF-1 $(50 \mathrm{ng} / \mathrm{ml})$ at $72 \mathrm{~h}$ incubation significantly augmented fusion index and differentiation index, but its biological response was completely prevented by previous incubation with SKI-2 (Figure 4B). These results demonstrate that the IGF-1-dependent myogenic process strictly depends on the activation of SK. To further assess the involvement of SK in the myogenic response evoked by IGF-1 in murine myoblasts, SK isoforms were specifically knocked-down by employing siRNA technology. In accordance with previous reports [10,22], specific siRNA treatment efficaciously reduced basal expression levels of SK1 (Figure 5A). The three-fold IGF-1-dependent increase of myogenin expression was totally abrogated when SK1 was downregulated by RNA interference, while caveolin-3 content, increased by the growth factor by approximately 3.5 -fold, was robustly decreased (approximately two-fold) (Figure 5A). Furthermore, the myogenic effect of IGF-1 was also reduced when SK2 was downregulated by specific RNA interference (Figure 5B). Indeed, Figure 5B shows that silencing of SK2 expression blunted the increase of myogenin and caveolin-3 content elicited by 50 ng/ml IGF-1 by approximately 1.5 -fold. The knocking down experiments support a role for both SK isoforms 


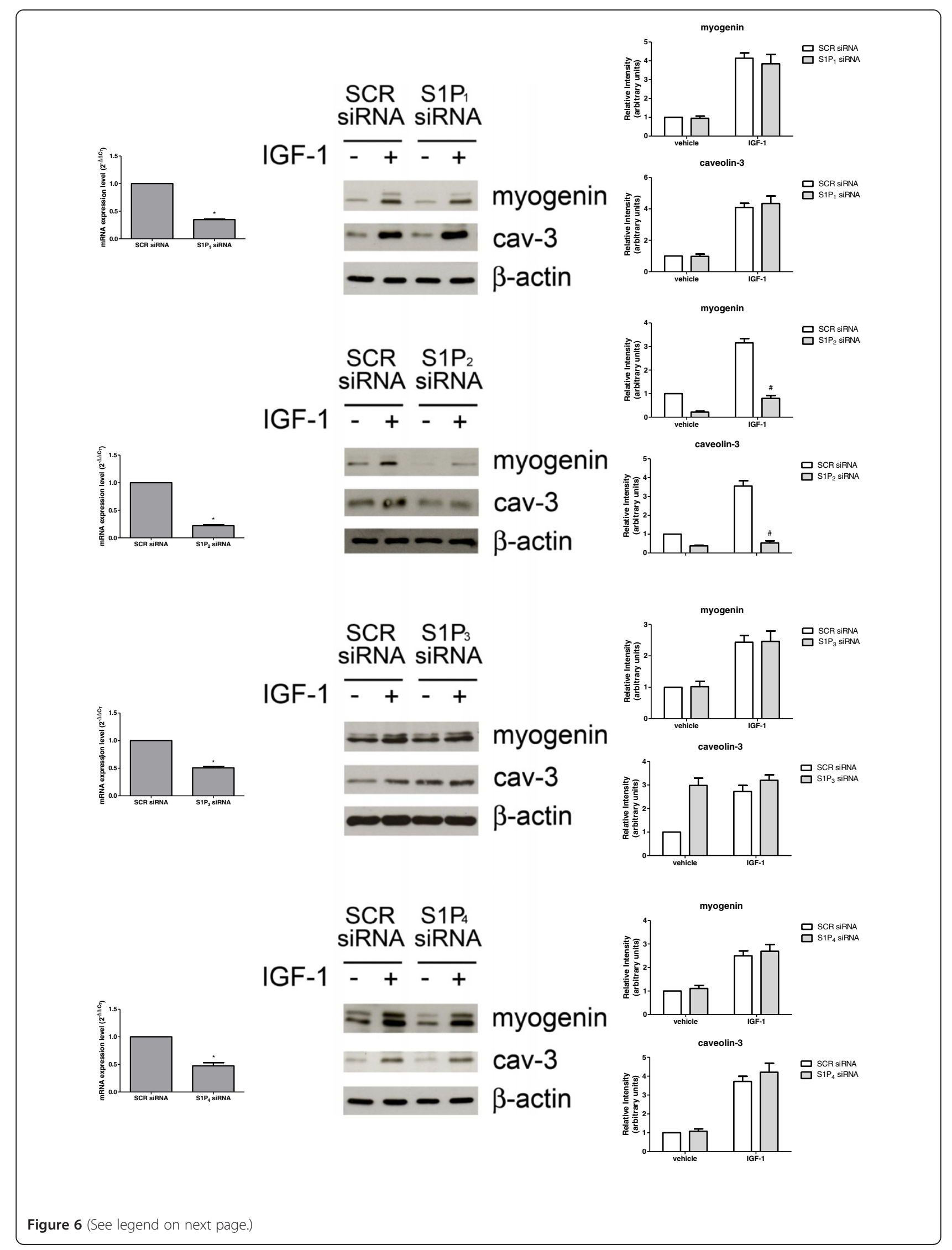


(See figure on previous page.)

Figure 6 Role of sphingosine 1-phosphate receptors in insulin-like growth factor-1-induced differentiation of mouse myoblasts. C2C12 myoblasts, transfected with scrambled (SCR) or with specific siRNA for individual sphingosine 1-phosphate receptors (S1PR), incubated in the absence (-) or in the presence (+) of $50 \mathrm{ng} / \mathrm{ml}$ insulin-like growth factor-1 (IGF-1) for the last $24 \mathrm{~h}$ of transfection, were checked for downregulation by real-time PCR (left). Middle, Western analysis of skeletal muscle marker proteins was performed in cell lysates. Equally loaded protein was checked by expression of the non-muscle-specific $\beta$ isoform of actin. A blot representative of three independent experiments with analogous results is shown. Right, densitometric analysis. The histograms represent band intensity of myogenin and caveolin-3 (cav-3) normalized to $\beta$-actin and reported as mean \pm SEM of three independent experiments, -fold change over control (time 24 h, no addition; set as 1 ). The effect of S1P $\mathrm{P}_{2}$ downregulation on IGF-1-induced expression of myogenin and cav-3 in IGF-1-challenged, S1P ${ }_{2}$-siRNA transfected cells versus IGF-1-challenged, SCR-siRNA transfected cells was statistically significant by Student's $t$ test (\#P<0.05); S1PR silencing was statistically significant in S1PR-siRNA transfected cells versus SCR-transfected cells ( $\left.{ }^{*} P<0.05\right)$.

in the differentiation driven by IGF-1. Moreover, the reduced effectiveness of SK2 downregulation in comparison to SK1 in preventing the myogenic effect of the growth factor suggests that the SK1 isoform plays a dominant role.

\section{The pro-myogenic effect of insulin-like growth factor-1 depends on sphingosine 1-phosphate ${ }_{2}$ receptor engagement}

We have previously demonstrated that exogenous S1P exerts pro-myogenic action in $\mathrm{C} 2 \mathrm{C} 12$ cells via engagement of the $\mathrm{S}_{2} \mathrm{P}_{2}$ receptor [7]. Since IGF-1 is able to increase S1P biosynthesis by activating both SK1 and SK2, and given that this event is crucial for the differentiating action of the growth factor, we investigated whether the myogenic action exerted by IGF-1 was mediated by $\mathrm{S}_{2} \mathrm{P}_{2}$ engagement in myoblasts. For this purpose, the expression of skeletal muscle marker proteins induced by 50 $\mathrm{ng} / \mathrm{ml}$ IGF-1 was evaluated in myoblasts where $\mathrm{S}_{2} \mathrm{P}_{2}$ was specifically downregulated by RNA interference. As shown in Figure 6, siRNA directed against $\mathrm{S}_{1} \mathrm{P}_{2}$, which significantly reduced the receptor expression, strongly attenuated the enhancement of myogenin elicited by IGF-1 (approximately three-fold) and abrogated the increase of caveolin-3. Conversely, the downregulation of the other receptor isoforms, $\mathrm{S}_{1} \mathrm{P}_{1}, \mathrm{~S}_{1} \mathrm{P}_{3}$ or $\mathrm{S}_{1} \mathrm{P}_{4}$, by specific siRNA did not alter the myogenic effect of the growth factor (Figure 6). The observed appreciable stimulation of the expression of caveolin-3 in unchallenged cells where $\mathrm{S}_{3} \mathrm{P}_{3}$ was downregulated (Figure 6) was in agreement with the previously demonstrated antimyogenic action mediated by this receptor subtype [7]. Altogether, these data support the view that transactivation of $\mathrm{S} \mathrm{P}_{2}$ by IGF-1 is implicated in the myogenic effect of the growth factor in myoblasts.

\section{Sphingosine kinase/sphingosine 1-phosphate signaling pathway is negatively implicated in the mitogenic effect of insulin-like growth factor-1}

Besides stimulating myogenesis, IGF-1 is also critically implicated in the control of myoblast growth. Therefore, we investigated whether the activation of the SK/S1P signaling pathway mediated by IGF-1 was also implicated in the mitogenic effect of the growth factor. Data presented in Figure 7A show that $50 \mathrm{ng} / \mathrm{ml}$ IGF-1 strongly stimulated cell proliferation, determined by measuring the incorporation of $\left[{ }^{3} \mathrm{H}\right]$ Thymidine into DNA, confirming the reported mitogenic effect of the growth factor in these cells [12]. Interestingly, when myoblasts were previously incubated with the specific pharmacological inhibitor of SK (SKI-2), the mitogenic effect of IGF-1 was significantly enhanced, suggesting a negative role of SK in modulating the proliferative response elicited by the growth factor. To further support this finding, individual SK isoforms were knocked-down by specific siRNA treatment (Figure 7B, insert). In accordance with the results obtained employing the pharmacological inhibitor SKI-2, data presented in Figure 7B demonstrate that knocking-down of SK1, as well as SK2, strongly increased the mitogenic effect elicited by IGF-1 by $90 \%$ and $50 \%$, respectively.

To establish whether the mechanism by which the SK/ S1P axis inhibits IGF-1-induced cell proliferation relies on receptor engagement, labelled thymidine incorporation experiments were performed in cells where individual S1PR were specifically knocked down by siRNA technology (Figure 8A). Results illustrated in Figure 8B clearly show that downregulation of $\mathrm{S}_{1} \mathrm{P}_{1}$ or $\mathrm{S}_{1} \mathrm{P}_{3}$ by RNA interference significantly enhanced DNA synthesis induced by $50 \mathrm{ng} / \mathrm{ml}$ IGF-1, whereas cell transfection with siRNA that specifically downregulated $\mathrm{S}_{1} \mathrm{P}_{2}$ or $\mathrm{S}_{1} \mathrm{P}_{4}$ did not impair the mitogenic effect of the growth factor. These data demonstrate that enhanced biosynthesis of S1P, due to SK1 and SK2 activation induced by IGF-1, is responsible for the engagement of $S 1 P_{1}$ and $S 1 P_{3}$ and is negatively implicated in the mitogenic effect of the growth factor.

\section{Sphingosine 1-phosphate lyase is not implicated in the insulin-like growth factor-1 biological role in skeletal muscle}

Finally, since cell response to IGF-1 was found to depend on S1P intracellular levels, we investigated whether SPL, responsible for the irreversible degradation of $\mathrm{S} 1 \mathrm{P}$, is 
A

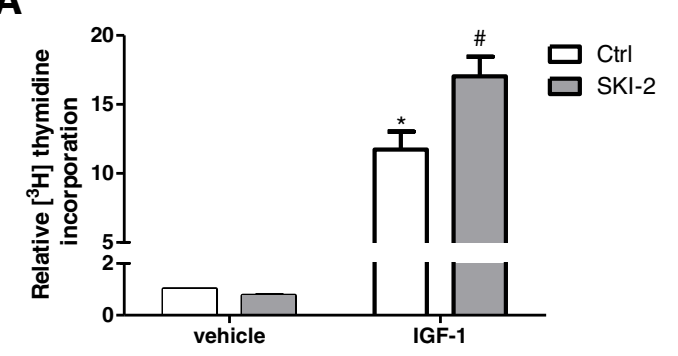

B
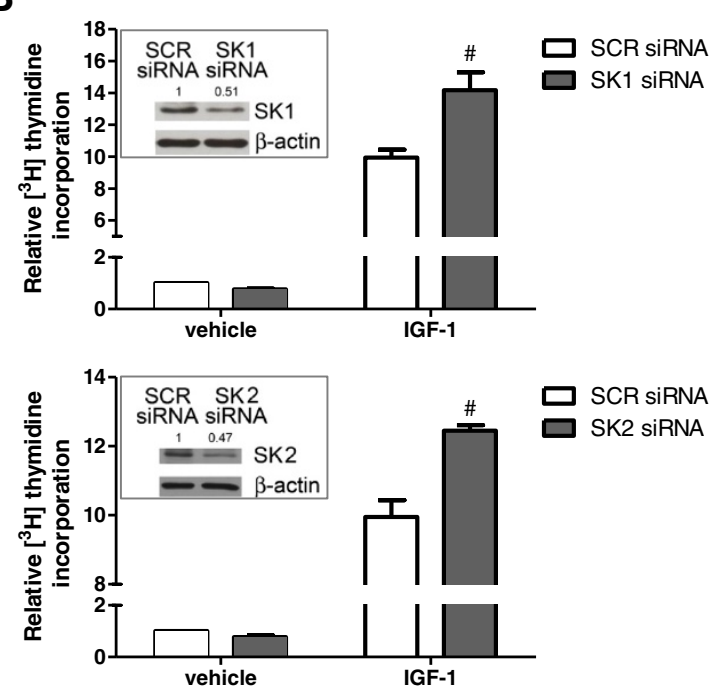

Figure 7 Role of sphingosine kinase in the mitogenic effect of insulin-like growth factor-1. (A) Serum-starved C2C12 myoblasts were pre-incubated for $30 \mathrm{~min}$ in the presence or absence of $1 \mu \mathrm{M} \mathrm{SKI-2}$ before being stimulated with $50 \mathrm{ng} / \mathrm{ml}$ insulin-like growth factor-1 (IGF-1) for 16 h. [ ${ }^{3} \mathrm{H}$ ]Thymidine $(1 \mu \mathrm{Ci} /$ well) was added during the last hour of incubation. $\left.{ }^{3} \mathrm{H}\right]$ Thymidine incorporation in untreated cells was $29893 \pm 1584 \mathrm{dpm}$. Results are reported as -fold change over control (vehicle, no addition; set as 1). Data are mean \pm SEM of at least three independent experiments performed in triplicate. The mitogenic effect of IGF-1 in challenged versus unchallenged cells was statistically significant by Student's $t$ test $(* P<0.05)$. The effect of SK inhibition on the mitogenic effect of IGF-1 in challenged cells versus control (no SKI-2, IGF-1 added) was statistically significant by Student's $t$ test (\#P<0.05). (B) Scrambled (SCR) or specific SK1- (upper panel) or SK2-siRNA (lower panel) transfected C2C12 cells were treated or not treated with $50 \mathrm{ng} /$ $\mathrm{ml} \mathrm{IGF-1} \mathrm{for} 16 \mathrm{~h}$. $\left.{ }^{3} \mathrm{H}\right]$ Thymidine $(1 \mu \mathrm{Ci} /$ well $)$ was added during the last hour of incubation. [ ${ }^{3} \mathrm{H}$ ]Thymidine incorporation was $20781 \pm 785 \mathrm{dpm}$ in control cells (untreated SCR-transfected cells). Results are reported as fold change over control (SCR siRNA, no addition; set as 1). Data are mean \pm SEM of at least four independent experiments performed in triplicate. The effect of SK downregulation on IGF-1-induced $\left.{ }^{3} \mathrm{H}\right]$ Thymidine incorporation in IGF-1-challenged, SK1- and SK2-siRNA transfected cells versus control (IGF-1 added, SCR-siRNA transfection) was statistically significant by Student's $t$ test $(\# P<0.05)$. Insert: cell extracts from C2C12 myoblasts transfected with SCR-, SK1-siRNA or SK2siRNA were employed for Western analysis using anti-SK1 or anti-SK2 antibodies. Equally loaded protein was checked by expression of $\beta$-actin. A blot representative of at least four independent experiments with analogous results is shown. Band intensity of SK1 or SK2 was normalized to $\beta$-actin and reported as -fold change over control (SCR siRNA, no addition; set as 1).
A

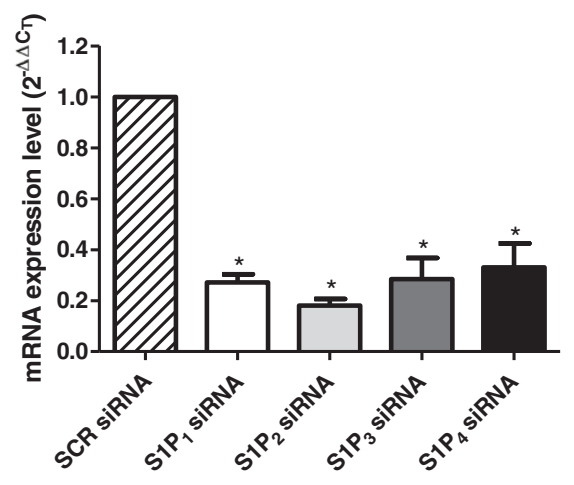

B

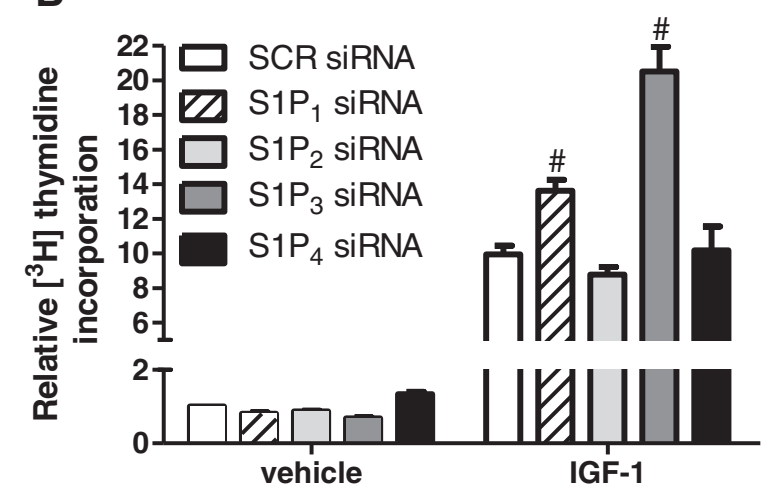

Figure 8 Role of sphingosine 1-phosphate receptors in the mitogenic effect of insulin-like growth factor-1. (A) Quantitative mRNA analysis was performed in C2C12 myoblasts transfected with non-specific scrambled (SCR) siRNA or with siRNA specific for sphingosine 1-phosphate receptors (S1PR); the content of housekeeping gene $18 \mathrm{~S}$ rRNA was analyzed in parallel. Results are expressed as -fold changes according to the $2^{-\Delta \Delta C T}$ method, utilizing each receptor subtype in cells transfected with SCR-siRNA as a calibrator. Data are mean \pm SEM of three independent experiments performed in triplicate. S1PR silencing in S1PR-siRNA transfected cells versus SCR-siRNA transfected cells was statistically significant $\left({ }^{*} P<0.05\right)$. (B) Serum-starved C2C12 myoblasts transfected with unspecific SCR-siRNA, or with specific siRNA for individual S1PR, were stimulated with $50 \mathrm{ng} / \mathrm{ml}$ insulin-like growth factor 1 (IGF-1) for $16 \mathrm{~h}$. $\left[{ }^{3} \mathrm{H}\right]$ Thymidine $(1 \mu \mathrm{Ci} /$ well) was added during the last hour of incubation. $\left[{ }^{3} \mathrm{H}\right]$ Thymidine incorporation was $19643 \pm 844 \mathrm{dpm}$ in control cells (untreated SCR-transfected cells). Results are reported as -fold change over control (SCR siRNA, no addition; set as 1). Data are mean \pm SEM of at least three independent experiments performed in triplicate. The effect of $S 1 \mathrm{P}_{1}$ and $\mathrm{S}_{1} \mathrm{P}_{3}$ downregulation on the IGF-1induced $\left[{ }^{3} \mathrm{H}\right]$ Thymidine incorporation in IGF-1-challenged, S1P $1^{-}$and $\mathrm{S}_{1} \mathrm{P}_{3}$-SiRNA transfected cells versus IGF-1-challenged, SCR-siRNA transfected cells was statistically significant by Student's $t$ test $(\# P<0.05)$.

involved in the biological effect of the growth factor. Western analysis data presented in Figure 9A show that treatment with $50 \mathrm{ng} / \mathrm{ml} \mathrm{IGF-1} \mathrm{did} \mathrm{not} \mathrm{affect} \mathrm{SPL} \mathrm{pro-}$ tein content in $\mathrm{C} 2 \mathrm{C} 12$ myoblasts. In the same figure it is shown that the increased expression of skeletal muscle 


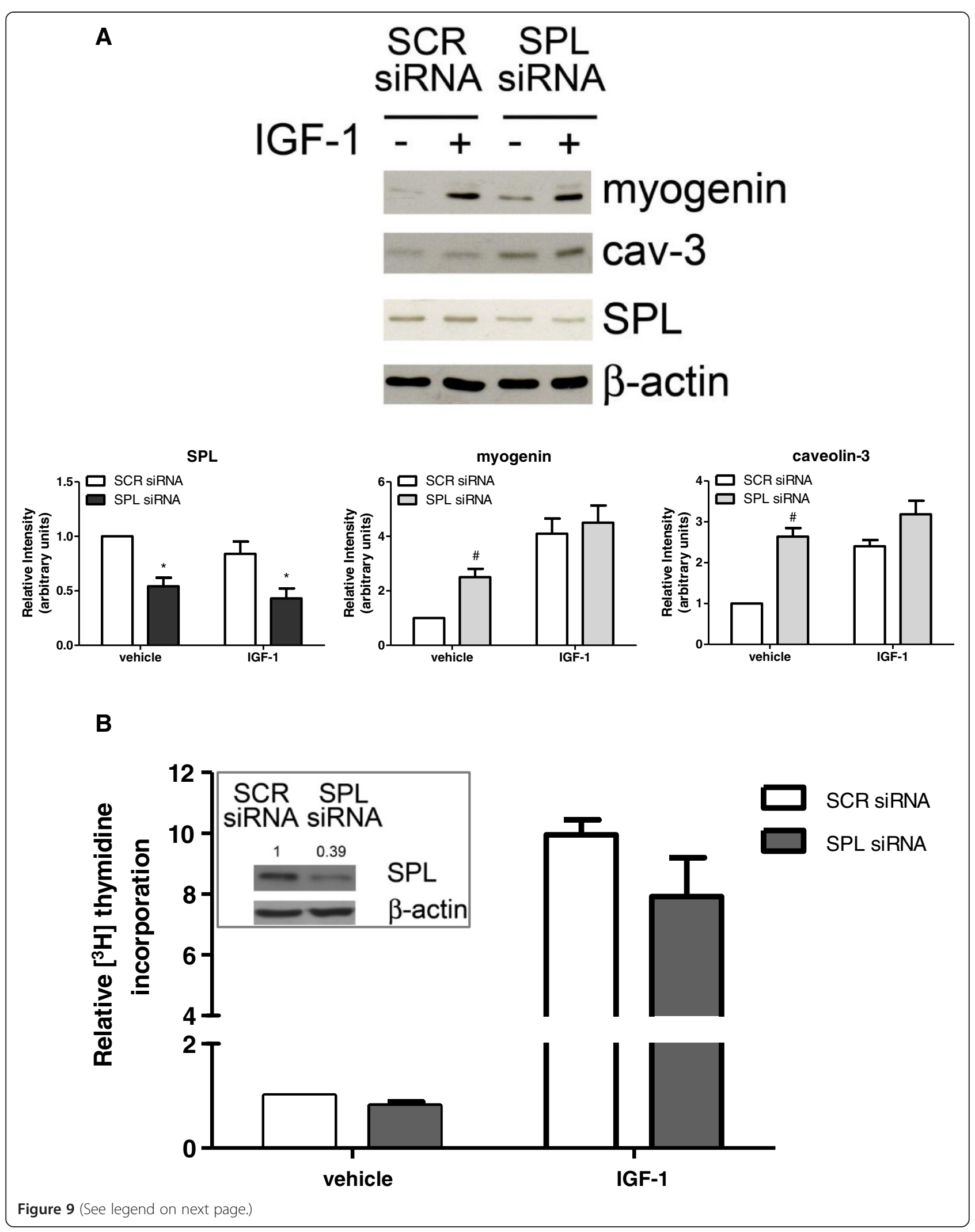


(See figure on previous page.)

Figure 9 Sphingosine 1-phosphate lyase is not involved in insulin-like growth factor-1 biological action in C2C12 myoblasts. (A) C2C12 myoblasts, transfected with scrambled (SCR) or sphingosine 1-phosphate lyase (SPL)-siRNA, were incubated in the absence (-) or in the presence (+) of $50 \mathrm{ng} / \mathrm{ml}$ insulin-like growth factor-1 (IGF-1) for the last $24 \mathrm{~h}$ of transfection. Western analysis of SPL and skeletal muscle marker proteins was performed in cell lysates. Equally loaded protein was checked by expression of the non-muscle-specific $\beta$ isoform of actin. A blot representative of three independent experiments with analogous results is shown. The histograms represent band intensity of SPL, myogenin and caveolin-3 (cav-3) normalized to $\beta$-actin and reported as mean \pm SEM of three independent experiments, -fold change over control (time 24 h, no addition; set as 1). SPL silencing in SPL-siRNA transfected cells versus SCR-siRNA transfected cells was statistically significant by Student's $t$ test ( ${ }^{P} P<0.05$ ). The effect of SPL downregulation on basal expression levels of myogenin and cav-3 in SPL-siRNA transfected, unchallenged cells versus SCR-siRNA transfected, unchallenged cells was statistically significant by Student's $t$ test (\#P<0.05). (B) Myoblasts transfected with unspecific SCR-siRNA or with specific SPL-siRNA were treated or not treated with $50 \mathrm{ng} / \mathrm{ml}$ IGF-1 for $16 \mathrm{~h}$. [ ${ }^{3} \mathrm{H}$ ]Thymidine (1 $\mu$ Ci/well) was added during the last hour of incubation. [ ${ }^{3} \mathrm{H}$ ]Thymidine incorporation was $21781 \pm 993 \mathrm{dpm}$ in control cells (untreated SCR-transfected cells). Results are reported as -fold change over control (SCR siRNA, no addition; set as 1). Data are mean \pm SEM of at least three independent experiments performed in triplicate. Insert: cell extracts from C2C12 myoblasts transfected with SCR- and SPL-siRNA were employed for Western analysis using anti-SPL antibodies. Equally loaded protein was checked by expression of $\beta$-actin. A blot representative of at least four independent experiments with analogous results is shown. Band intensity of SPL was normalized to $\beta$-actin and reported as -fold change over control (SCR siRNA, no addition; set as 1).

marker proteins induced by $50 \mathrm{ng} / \mathrm{ml}$ IGF-1 was not affected by specific downregulation of SPL by RNA interference, ruling out the involvement of this enzyme in the control of the IGF-1 myogenic effect. It is interesting to note that knocking-down of SPL enhanced basal expression levels of the myogenic markers by approximately two-fold, in favor of the participation of the enzyme in the regulation of intracellular levels of S1P, whose myogenic effect has been previously demonstrated [7,22].

We then investigated the role of SPL in IGF-1-induced DNA synthesis. For this purpose, labelled thymidine incorporation experiments were performed in cells where SPL had been specifically downregulated by employing siRNA technology. Data presented in Figure 9B clearly show that cell transfection with siRNA that specifically downregulated SPL (Figure 9B, insert) did not impair the mitogenic effect of IGF-1, demonstrating that SPL does not participate in the IGF-1-directed regulation of S1P metabolism.

\section{Discussion}

The IGF-1 signaling pathway plays a key role in the regulation of skeletal muscle growth, in differentiation, and in the maintaining of tissue homeostasis. Intriguingly, this growth factor stimulates two key processes such as myoblast proliferation and differentiation which are mutually exclusive events during myogenesis [12]. The results presented here for the first time demonstrate that the SK/S1P signaling pathway is involved in the regulation of the biological action exerted by IGF-1. This finding is crucial for the timely regulation of cell proliferation and differentiation. Indeed, experimental evidence is provided that activation of SK followed by transactivation of $\mathrm{S}_{2} \mathrm{P}_{2}$ elicited by the growth factor is required for its pro-myogenic action whereas the parallel engagement of $\mathrm{S}_{1} \mathrm{P}_{1}$ and $\mathrm{S}_{1} \mathrm{P}_{3}$ reduces its mitogenic effect. Notably, the IGF1-induced SK/S1P axis appears to exhibit the unique property of regulating two opposite biological effects elicited by IGF-1 in myoblasts - transducing its myogenic response on one side and inhibiting its mitogenic effect on the other - therefore acting as an efficacious switch to stop proliferation and triggering differentiation through the concomitant activation of individual S1PR subtypes.

Previously we have demonstrated in these cells that the final biological outcome of PDGF, which plays a crucial role in skeletal muscle, depends on SK/S1P axis activation [11]. Indeed, the activation of SK1 induced by PDGF resulted in the transactivation of $\mathrm{S}_{\mathrm{P}} \mathrm{P}_{1}$, responsible for the chemotactic response elicited by PDGF and also for the negative regulation of its mitogenic effect. Despite the overlapping role of the SK/S1P axis in inhibiting the mitogenic effect of both PDGF and IGF-1, we show here that the negative regulation of IGF-1-induced proliferation, beside being dependent on $\mathrm{S}_{1} \mathrm{P}_{1}$, relies also on $\mathrm{S}_{1} \mathrm{P}_{3}$ engagement. Moreover, in this study, we have established that the IGF-1 myogenic effect is dependent on the engagement of $\mathrm{S}_{2} \mathrm{P}_{2}$, which has been already shown to be coupled to the pro-differentiating activity of exogenous and endogenous S1P in these cells $[7,22]$.

Interestingly, here we provide the first evidence of the involvement of SK2 in S1P inside-out signaling in myoblasts. Indeed SK2, similarly to the SK1 isoform, was found to be required for transmitting the pro-myogenic effect of IGF-1, highlighting a key role of this enzyme isoform in skeletal muscle biology. In this regard, the parallel regulation of mitogenesis and migration elicited by PDGF was found to rely exclusively on the specific activation of SK1 [11]. SK1 and SK2 have different developmental expression, adult tissue distribution and subcellular localization patterns. Such differences are in line with the concept that, although the two enzymes use the same substrate and generate the same product, they can mediate distinct biological events. SK1 is almost 
universally associated with the induction of cell survival and proliferation [23], whereas SK2 overexpression suppresses cell growth and enhances apoptosis [24]. Studies performed in mesangial cells supported the proapoptotic role of SK2, demonstrating that SK2-null cells are more resistant to staurosporine-induced apoptosis than wild-type or SK1-null cells [25]. Our findings corroborate the notion that SK isoforms may instead have overlapping functions. Indeed, data obtained by preincubation with the pharmacological inhibitor SKI-2 that does not distinguish between the two SK isoforms, and by specific silencing of SK1 or SK2 isoforms demonstrate the involvement of both enzyme isoforms in the promyogenic effect of IGF-1. In accordance, it has been recently reported that SK1 and SK2 are equally required for epidermal growth factor-induced migration of breast cancer cells [26] and TGF $\beta$-induced migration and invasion of esophageal cancer cells [27].

Data previously reported in the literature sustain the existence of a functional cross-talk between IGF-1 and S1P signaling pathways. IGF-1 was shown to elicit ERK1/2 activation by stimulating SK1-dependent transactivation of $\mathrm{S}_{1} \mathrm{P}_{1}$ even though the biological effect of S1P-dependent ERK1/2 activation was not addressed $[28,29]$. In this study, for the first time, we identified the involvement of the SK/S1PR axis in the biological action of IGF-1, that intriguingly in its molecular mechanism of action implies ERK1/2-dependent phosphorylation of SK1.

It is worth noting that exogenous S1P has been previously reported to counteract the chemotactic action exerted by IGF-1 in myoblasts via ligation of $\mathrm{S}_{2} \mathrm{P}_{2}$ [8]. The involvement reported in this paper of the SK/S1P axis in mediating IGF-1 biological effects is not in constrast with the previous finding. Indeed, it appears that the selective spatial control of S1P formation inside myoblasts following stimulation with different cues is crucial for the generation of a specific biochemical response. In this regard, we recently demonstrated that endogenous S1P that is formed in response to PDGF challenge stimulates cell motility via $\mathrm{S}_{1} \mathrm{P}_{1}[11]$, whereas exogenous $\mathrm{S} 1 \mathrm{P}$ was previously found to inhibit motility of the same cell type acting through $\mathrm{S}_{2} \mathrm{P}_{2}$ [8]. Moreover, we recently demonstrated that, in $\mathrm{C} 2 \mathrm{C} 12$ myoblasts, the S1P signaling pathway, which physiologically accounts for myogenic differentiation via $\mathrm{S}_{1} \mathrm{P}_{2}$, is redirected by the cytokine TGF $\beta$ to act primarily via the pro-fibrotic $\mathrm{S}_{1} \mathrm{P}_{3}$. Indeed, consequently to TGF $\beta$ treatment, $\mathrm{S}_{1} \mathrm{P}_{3}$ then becomes the prevailing expressed receptor, thus promoting myoblast transdifferentiation to myofibroblasts [9].

Finally, we investigate the possible involvement of SPL in skeletal muscle biology. A previous study performed by Herr and colleagues [30] demonstrated that normal S1P catabolism is required for Drosophila muscle development, given that SPL-null mutants exhibited pattern abnormalities in the dorsal longitudinal flight muscles of the adult thorax. Moreover, SPL was recently identified as a potential therapeutic target for ischemiareperfusion injury of the heart [31]. Using a genetic SPL knock-out mouse model and a chemical inhibitor, Bandhuvula and colleagues [31] demonstrated that ischemia caused the activation of SPL in cardiac tissue resulting in the reduction of the levels of S1P, thus promoting cardiomyocyte apoptosis. For the first time, we have demonstrated in this paper that mouse myoblasts express SPL. Furthermore, we provide evidence that this enzyme contributes to the regulation of intracellular levels of the pro-myogenic S1P, as knocking-down of the enzyme resulted in the upregulation of the basal expression levels of myogenic markers. This is in agreement with the concept that, in this experimental condition, S1P intracellular levels are enhanced and consequently the mediatedpromyogenic action is potentiated [7,22]. However, from this study, SPL appears to be disengaged from IGF-1mediated biological effects as its specific downregulation did not affect either myogenesis or proliferation induced by the growth factor.

Taking into account the different S1PR patterns expressed in satellite cells and murine myoblasts, and considering that exogenous S1P is mitogenic in satellite cells whereas it acts as an anti-mitogenic and prodifferentiating cue in myoblasts [6,7], it will be interesting to further investigate whether the individuated crosstalk between the IGF-1 and S1P signaling pathway observed here also takes place in satellite cells and mediates a specific IGF-1-induced biological response

\section{Conclusions}

Collectively, our findings support the notion that the SK/ S1P axis, via the engagement of S1PR, exhibits the unique ability to regulate two opposite biological effects elicited by IGF-1 in myoblasts - transducing its myogenic response on one side and inhibiting its mitogenic effect on the other. These results increase our knowledge on the mechanism by which IGF-1 regulates skeletal muscle regeneration.

\section{Abbreviations \\ AEBSF: 4-(2-aminoethyl)benzenesulfonyl fluoride; BSA: bovine serum albumin; DMEM: Dulbecco's modified Eagle's medium; IGF-1: Insulin-like growth factor- 1; MHC: myosin heavy chain; PBS: phosphate-buffered saline; \\ PCR: polymerase chain reaction; PDGF: platelet-derived growth factor; S1P: sphingosine 1-phosphate; S1PR: sphingosine 1-phosphate receptors; SK: sphingosine kinase; SPL: sphingosine 1-phosphate lyase; TGF: transforming growth factor; TNF: tumor necrosis factor.}

Competing interests

The authors declare that they have no competing interests.

\section{Authors' contributions}

$\mathrm{CB}$ performed the experiments, analyzed the data and wrote the article. FC performed the experiments and analyzed the data. SB performed the 
experiments. CD analyzed the data and wrote the article. PB designed the research and wrote the article. All the authors read and approved the final manuscript.

\section{Acknowledgments}

This research was supported by grants from Italian Ministry of University and Scientific Research (PRIN2007), Telethon Italy (GGP08053), University of Florence, and Ente Cassa di Risparmio di Firenze.

Received: 16 February 2012 Accepted: 21 June 2012 Published: 12 July 2012

\section{References}

1. Lebman DA, Spiegel S: Cross-talk at the crossroads of sphingosine-1phosphate, growth factors, and cytokine signaling. J Lipid Res 2008, 49:1388-1394.

2. Fyrst H, Saba JD: Sphingosine-1-phosphate lyase in development and disease: sphingolipid metabolism takes flight. Biochim Biophys Acta 2008 1781:448-458.

3. Le Stunff H, Peterson C, Liu H, Milstien S, Spiegel S: Sphingosine-1phosphate and lipid phosphohydrolases. Biochim Biophys Acta 2002, 1582:8-17.

4. Bruni $P$, Donati $C$ : Pleiotropic effects of sphingolipids in skeletal muscle. Cell Mol Life Sci 2008, 65:3725-3736.

5. Nagata $Y$, Kobayashi H, Umeda M, Ohta N, Kawashima S, Zammit PS, Matsuda R: Sphingomyelin levels in the plasma membrane correlate with the activation state of muscle satellite cells. J Histochem Cytochem 2006, 54:375-384

6. Calise S, Blescia S, Cencetti F, Bernacchioni C, Donati C, Bruni P: Sphingosine 1-phosphate stimulates proliferation and migration of satellite cells: role of S1P receptors. Biochim Biophys Acta 2012

1823:439-450

7. Donati C, Meacci E, Nuti F, Becciolini L, Farnararo M, Bruni P: Sphingosine 1phosphate regulates myogenic differentiation: a major role for S1P2 receptor. FASEB J 2005, 19:449-451.

8. Becciolini L, Meacci E, Donati C, Cencetti F, Rapizzi E, Bruni P: Sphingosine 1-phosphate inhibits cell migration in C2C12 myoblasts. Biochim Biophys Acta 2006, 1761:43-51.

9. Cencetti F, Bernacchioni C, Nincheri P, Donati C, Bruni P: Transforming growth factor-beta1 induces transdifferentiation of myoblasts into myofibroblasts via up-regulation of sphingosine kinase-1/S1P3 axis. Mol Biol Cell 2010, 21:1111-1124.

10. Donati C, Nincheri P, Cencetti F, Rapizzi E, Farnararo M, Bruni P: Tumor necrosis factor-alpha exerts pro-myogenic action in $\mathrm{C} 2 \mathrm{C} 12$ myoblasts via sphingosine kinase/S1P2 signaling. FEBS Lett 2007, 581:4384-4388.

11. Nincheri $P$, Bernacchioni $C$, Cencetti F, Donati C, Bruni P: Sphingosine kinase-1/S1P1 signalling axis negatively regulates mitogenic response elicited by PDGF in mouse myoblasts. Cell Signal 2010, 22:1688-1699.

12. Duan $\mathrm{C}$, Ren H, Gao S: Insulin-like growth factors (IGFs), IGF receptors, and IGF-binding proteins: roles in skeletal muscle growth and differentiation. Gen Comp Endocrinol 2010, 167:344-351.

13. Murate T, Banno Y, T-Koizumi K, Watanabe K, Mori N, Wada A, Igarashi Y, Takagi A, Kojima T, Asano H, Akao Y, Yoshida S, Saito H, Nozawa Y: Cell type-specific localization of sphingosine kinase-1a in human tissues. J Histochem Cytochem 2001, 49:845-855.

14. Igarashi N, Okada T, Hayashi S, Fujita T, Jahangeer S, Nakamura S: Sphingosine kinase-2 is a nuclear protein and inhibits DNA synthesis. J Biol Chem 2003, 278:46832-46839.

15. Pitson SM, Moretti PA, Zebol JR, Lynn HE, Xia P, Vadas MA, Wattenberg BW: Activation of sphingosine kinase-1 by ERK1/2-mediated phosphorylation. EMBO J 2003, 22:5491-5500.

16. Bektas M, Allende ML, Lee BG, Chen W, Amar MJ, Remaley AT, Saba JD, Proia RL: Sphingosine 1-phosphate lyase deficiency disrupts lipid homeostasis in liver. J Biol Chem 2010, 285:10880-10889.

17. Olivera A, Rosenthal J, Spiegel S: Sphingosine kinase from Swiss 3T3 fibroblasts: a convenient assay for the measurement of intracellular levels of free sphingoid bases. Anal Biochem 1994, 223:306-312.

18. Donati C, Cencetti F, Nincheri P, Bernacchioni C, Brunelli S, Clementi E, Cossu G, Bruni P: Sphingosine 1-phosphate mediates proliferation and survival of mesoangioblasts. Stem Cells 2007, 25:1713-1719.
19. Livak KJ, Schmittgen TD: Analysis of relative gene expression data using real-time quantitative PCR and the 2(-Delta Delta $C(T))$ method. Methods 2001, 25:402-408.

20. Anastasi S, Giordano S, Sthandier O, Gambarotta G, Maione R, Comoglio P, Amati P: A natural hepatocyte growth factor/scatter factor autocrine loop in myoblast cells and the effect of the constitutive Met kinase activation on myogenic differentiation. J Cell Biol 1997, 137:1057-1068.

21. Li YP, Schwartz RJ: TNF-alpha regulates early differentiation of $\mathrm{C} 2 \mathrm{C} 12$ myoblasts in an autocrine fashion. FASEB J 2001, 15:1413-1415.

22. Meacci $E$, Nuti F, Donati C, Cencetti F, Farnararo M, Bruni P: Sphingosine kinase activity is required for myogenic differentiation of $\mathrm{C} 2 \mathrm{C} 12$ myoblasts. J Cell Physiol 2008, 214:210-220.

23. Pyne NJ, Pyne S: Sphingosine 1-phosphate and cancer. Nat Rev Cancer 2010, 10:489-503.

24. Okada T, Ding G, Sonoda H, Kajimoto T, Haga Y, Khosrowbeygi A, Gao S, Miwa N, Jahangeer S, Nakamura S: Involvement of N-terminal-extended form of sphingosine kinase-2 in serum-dependent regulation of cell proliferation and apoptosis. J Biol Chem 2005, 280:36318-36325.

25. Hofmann LP, Ren S, Schwalm S, Pfeilschifter J, Huwiler A: Sphingosine kinase- 1 and -2 regulate the capacity of mesangial cells to resist apoptotic stimuli in an opposing manner. Biol Chem 2008, 389:1399-1407.

26. Hait NC, Sarkar S, Le Stunff H, Mikami A, Maceyka M, Milstien S, Spiegel S: Role of sphingosine kinase-2 in cell migration toward epidermal growth factor. J Biol Chem 2005, 280:29462-29469.

27. Miller AV, Alvarez SE, Spiegel S, Lebman DA: Sphingosine kinases and sphingosine-1-phosphate are critical for transforming growth factor beta-induced extracellular signal-regulated kinase 1 and 2 activation and promotion of migration and invasion of esophageal cancer cells. $\mathrm{Mol}$ Cell $\mathrm{Bio} / 2008,28: 4142-4151$.

28. El-Shewy HM, Johnson KR, Lee MH, Jaffa AA, Obeid LM, Luttrell LM: Insulinlike growth factors mediate heterotrimeric $\mathrm{G}$ protein-dependent ERK1/2 activation by transactivating sphingosine 1-phosphate receptors. $\mathrm{J}$ Biol Chem 2006, 281:31399-31407.

29. El-Shewy HM, Lee MH, Obeid LM, Jaffa AA, Luttrell LM: The insulin-like growth factor type 1 and insulin-like growth factor type 2/mannose-6phosphate receptors independently regulate ERK1/2 activity in HEK293 cells. J Biol Chem 2007, 282:26150-26157.

30. Herr DR, Fyrst H, Phan V, Heinecke K, Georges R, Harris GL, Saba JD: Sply regulation of sphingolipid signaling molecules is essential for Drosophila development. Development 2003, 130:2443-2453.

31. Bandhuvula P, Honbo N, Wang GY, Jin ZQ, Fyrst H, Zhang M, Borowsky AD, Dillard L, Karliner JS, Saba JD: S1P lyase: a novel therapeutic target for ischemia-reperfusion injury of the heart. Am J Physiol Heart Circ Physiol 2011, 300:H1753-H1761.

doi:10.1186/2044-5040-2-15

Cite this article as: Bernacchioni et al:: Sphingosine kinase/sphingosine 1-phosphate axis: a new player for insulin-like growth factor-1-induced myoblast differentiation. Skeletal Muscle 2012 2:15.

\section{Submit your next manuscript to BioMed Central and take full advantage of:}

- Convenient online submission

- Thorough peer review

- No space constraints or color figure charges

- Immediate publication on acceptance

- Inclusion in PubMed, CAS, Scopus and Google Scholar

- Research which is freely available for redistribution 